\title{
DESENVOLVIMENTO DE MÉTODO DE ENSAIO DE DESGASTE ABRASIVO POR DESLIZAMENTO*
}

\author{
João Henrique de Andrade Lima ${ }^{1}$ \\ Wilian da Silva Labiapari² \\ Tarcísio Reis de Oliveira ${ }^{3}$
}

\begin{abstract}
Resumo
Dentre os mecanismos de desgaste existentes o desgaste por abrasão é responsável por cerca de $50 \%$ de todo o desgaste gerado. Alinhado à busca do desenvolvimento de novos mercados para o aço inoxidável, foi desenvolvida uma metodologia, para a medição da taxa de desgaste abrasivo de diferentes aços. Uma politriz foi escolhida para o ensaio devido à possibilidade de controlar a força, tipo de abrasivo, vazão de água, tempo e velocidade de rotação do disco. Para o ensaio foram preparados corpos de prova do aço P410D com dimensões de 40x40mm. Os corpos de prova foram fixados em suportes de baquelite e este conjunto foi acoplado junto à politriz. Após a escolha dos parâmetros ideais para o teste foram realizados testes comparando a taxa de desgaste de diferentes tipos de aços permitindo ranqueá-los de acordo com sua resistência ao desgaste abrasivo.
\end{abstract}

Palavras-chave: Aço Inoxidável; Desgaste abrasivo; Tribologia.

\section{DEVELOPMENT SLIDING ABRASIVE WEAR TEST}

\begin{abstract}
The abrasive wear is responsible for about $50 \%$ of all wear. In an attempt to new markets for stainless steel, a method for measuring the rate of abrasive wear of different steels it was developed. Polishing equipment was selected for testing due to the possible of controlling the load, type of abrasive, water flow, time and disk rotational speed. For the test, they were prepared samples of stainless steel (P410D) with dimensions of $40 \times 40 \mathrm{~mm}$. These specimens were fixed in bakelite brackets and this set was engaged on the polishing equipment. After selecting the optimal parameters for the test, it was performed tests comparing the different types of steel and theirs wear rate.
\end{abstract}

Keywords: Stainless steel; Abrasive wear; Tribology.

1 Graduando em Engenharia Metalúrgica, Aluno de Iniciação Científica, Centro Universitário do Leste de Minas Gerais - UNILESTE, Coronel Fabriciano, Minas Gerais, Brasil.

2 Engenheiro, Mestre e Doutor em Engenharia Mecânica, Pesquisador da APERAM, Timóteo, Minas Gerais, Brasil.

3 Engenheiro, Mestre e Doutor em Ciência dos Materiais, Pesquisador da APERAM e Professor no Centro Universitário do Leste de Minas Gerais, Timóteo, Minas Gerais, Brasil. 


\section{INTRODUÇÃO}

Estima-se que cerca de 1 a $5 \%$ do PIB mundial sejam gastos com atrito e desgastes em geral [1].

O desgaste de equipamentos industriais, agrícolas e do setor de mineração, representa uma grande despesa com manutenção, substituição de equipamentos e componentes. Em pesquisa recente sobre as 200 maiores minas brasileiras, em 50 delas o investimento necessário para a manutenção da frota consumiu cerca de $\mathrm{R} \$ 317,7$ milhões no ano de 2014 e o desgaste foi o principal responsável pela degradação dos equipamentos [2]. Além do desgaste, muitas vezes ocorre ainda o superdimensionamento de equipamentos diminuindo a capacidade de produção do mesmo. Desta forma o desgaste ainda é responsável por várias despesas indiretas que não são contabilizadas. O setor de mineração, em específico, viveu uma alta no mercado devido à elevação dos preços das commodities e da demanda dos principais minérios. A partir do ano de 2008 houve uma queda de demanda e consequentemente nos preços dessas commodities. Para aumentar a competitividade e reduzir as despesas, desde então grandes empresas do setor tem procurado no mercado, alternativas de materiais mais resistentes ao desgaste. $A$ severidade do desgaste é muito sensível à mudança dos agentes envolvidos. Por isso muitas vezes se faz necessário à realização dos ensaios visando à representação de ambientes específicos procurando controlar ao máximo de variáveis possíveis do sistema. Diante da falta de um ensaio universal para medição de desgaste, foi proposto o desenvolvimento de uma metodologia capaz de determinar taxas de desgaste de forma rápida e confiável e que seja possível representar um tribossistema semelhante ao de uma mineração.

\subsection{Revisão da Literatura}

O desgaste pode ser definido como a deterioração de uma superfície ocasionando a perda progressiva de material, devido ao movimento relativo de dois ou mais corpos, superfícies ou substancias [3].

Por definição o desgaste abrasivo ocorre devido ao contato de partículas ou protuberâncias duras contra uma superfície em movimento relativo [4].

Atualmente o contato entre as partículas abrasivas e a superfície de desgaste tem sido classificado em dois mecanismos segundo a dinâmica da partícula sendo dividido entre desgaste abrasivo por deslizamento ou por rolamento de partículas. Esta classificação baseia-se nas pistas de desgaste geradas pelas partículas abrasivas na superfície do corpo de prova [5]. No desgaste abrasivo por deslizamento as partículas abrasivas estão fixas em uma das superfícies (Figura 1a). Desta forma, elas só podem deslizar sobre o corpo-de-prova. Já no desgaste abrasivo por rolamento, estas partículas estão soltas podendo se mover livremente em um movimento de rolamento (Figura 1b) [6]. 


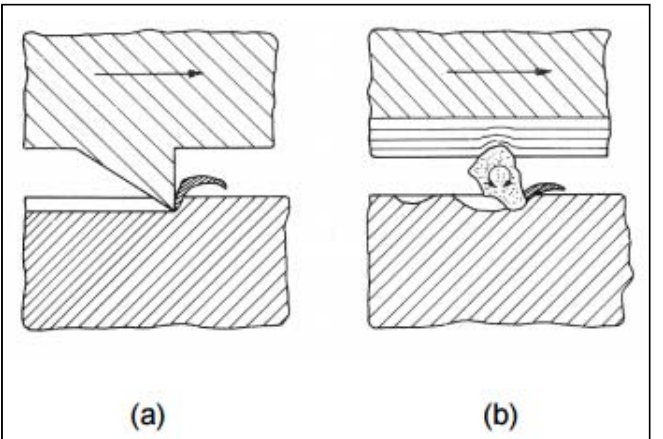

Figura 1. Mecanismos de desgaste: a) Deslizamento e b) Rolamento.

Fonte: Zum Gahr.

Para a simulação de desgaste em laboratório, controlar e medir todas as variáveis que podem influenciar o desgaste é muito importante. Pois pequenos desvios nas condições ensaiadas podem ocasionar mudanças radicais nas taxas de desgaste [5]. Mesmo nos ensaios normatizados se faz necessário a introdução de alguns elementos para adaptar o ensaio para uma condição que seja semelhante ao que ocorre na realidade. Os ensaios mais comuns regidos por normas são: Bloco-disco ASTM G77; Pino-disco - ASTM G99; Roda de Borracha - ASTM G65.

\section{MATERIAIS E MÉTODOS}

Para o desenvolvimento da metodologia proposta o equipamento utilizado como tribômetro foi uma politriz (Figura 2). Este equipamento foi escolhido devido à possibilidade de controlar os parâmetros desejados para um ensaio de desgaste.

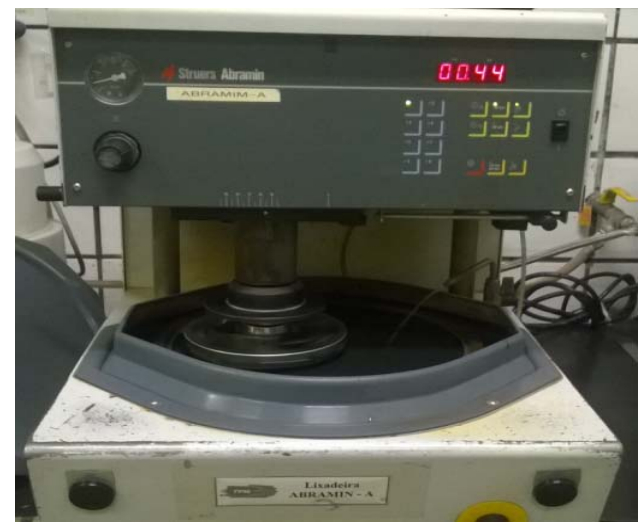

Figura 2. Politriz utilizada para realização dos testes.

Para a utilização da politriz nos ensaios foram confeccionados suportes poliméricos de baquelite (Figura 3a) para que os corpos de prova fossem acoplados no suporte de amostras da politriz (Figura 3b).
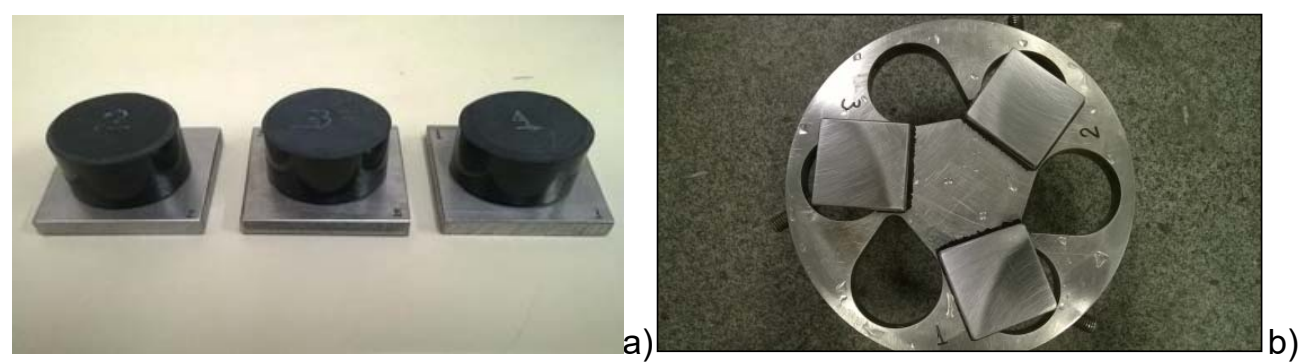

Figura 3. Amostras fixadas: a) nos suportes de baquelite, b)no suporte de amostras. 
Os estudos foram realizados no Centro de Pesquisas da Aperam - Timóteo/MG.

Para o desenvolvimento da metodologia, foi utilizado como material padrão, o aço inoxidável ferrítico P410D. Foram retiradas amostras nas dimensões de 40x40mm que posteriormente foram fixadas nos suportes poliméricos.

O desgaste abrasivo é um fenômeno de superfície, por este motivo, o acabamento dado na indústria poderia gerar flutuação no comportamento das amostras. Para eliminar este problema as amostras tinham suas superfícies lixadas com lixa d'agua de carbeto de silício (SiC) com granulação 120.

Após a preparação dos corpos de prova, os mesmos foram divididos em cinco grupos sendo cada grupo submetido ao ensaio em diferentes condições de carga e tempo de ciclo (Tabela 1). Cada ensaio é constituído de 10 ciclos de lixamento em cada condição determinada.

Tabela 1. Condições de ensaio

\begin{tabular}{ccccccc}
\hline Grupo & $\begin{array}{c}\text { Tempo } \\
{[\mathrm{min}]}\end{array}$ & $\begin{array}{c}\text { Carga } \\
{[\mathrm{N}]}\end{array}$ & $\begin{array}{c}\text { Vazão } \\
{[\mathrm{ml} / \mathbf{s}]}\end{array}$ & RPM & Lixa & $\begin{array}{c}\text { Tipo de } \\
\text { Abrasivo }\end{array}$ \\
\hline $\mathrm{A}$ & 1 & 100 & 260 & 150 & 120 & $\mathrm{SiC}$ \\
\hline $\mathrm{B}$ & 2 & 50 & 260 & 150 & 120 & $\mathrm{SiC}$ \\
\hline $\mathrm{C}$ & 2 & 100 & 260 & 150 & 120 & $\mathrm{SiC}$ \\
\hline $\mathrm{D}$ & 2 & 150 & 260 & 150 & 120 & $\mathrm{SiC}$ \\
\hline $\mathrm{E}$ & 3 & 100 & 260 & 150 & 120 & $\mathrm{SiC}$ \\
\hline
\end{tabular}

Ao final de cada ciclo os corpos de prova são pesados para determinação da taxa de desgaste. Esta etapa do desenvolvimento teve como objetivo, verificar se as condições de ensaio propostas seriam capazes de atingir o regime permanente de desgaste. Após todos os ensaios todos os corpos de prova foram submetidos à análise perfilométrica para a verificação do desempenho do abrasivo. Para realização dos ensaios comparativos, foi selecionada a condição na qual o abrasivo apresentou o melhor desempenho.

Para a validação do ensaio foi necessário verificar se por meio deste seria possível ranquear diferentes materiais, e para tal, foram selecionados os aços citados na (Tabela 2).

Tabela 2. Composição química dos aços utilizados

\begin{tabular}{|c|c|c|c|c|c|c|c|c|c|}
\hline \multirow{2}{*}{$\begin{array}{c}\text { Aço } \\
\text { Aperam }\end{array}$} & \multicolumn{9}{|c|}{ Composição Química } \\
\hline & $\begin{array}{l}\text { C (\%) } \\
\text { Máx }\end{array}$ & $\mathrm{Cr}(\%)$ & $\begin{array}{c}\text { Si (\%) } \\
\text { Máx }\end{array}$ & Mn (\%) & $\mathrm{Ni}(\%)$ & $\begin{array}{c}\text { Nb (\%) } \\
\text { Máx }\end{array}$ & $\begin{array}{l}\text { Ti (\%) } \\
\text { Máx }\end{array}$ & $\mathrm{Cu}(\%)$ & $\mathbf{N}(\%)$ \\
\hline $\mathrm{P} 410 \mathrm{M}^{*}$ & 0,02 & $11,0-11,7$ & 0,7 & & $\begin{array}{c}0,5 \\
\text { (Máx) }\end{array}$ & -- & -- & -- & $\begin{array}{c}\text { 0,025(Má } \\
\text { x) }\end{array}$ \\
\hline P410D & 0,02 & $11,0-11,7$ & 0,7 & & $\begin{array}{c}0,5 \\
\text { (Máx) }\end{array}$ & -- & -- & -- & $\begin{array}{c}0,025 \text { (Má } \\
\text { x) }\end{array}$ \\
\hline P398 & 0,01 & 0,03 & 1,0 & 2,0 & $3,5-5,5$ & -- & 0,16 & -- & $0,05-0,2$ \\
\hline P399 & 0,05 & 0,03 & 1,0 & 2,0 & $4,5-6,5$ & -- & -- & $0,1-0,6$ & $0,14-0,2$ \\
\hline A36 & 0,28 & -- & 0,04 & $0,6-0,9$ & -- & -- & -- & -- & -- \\
\hline
\end{tabular}




\section{RESULTADOS E DISCUSSÃO}

\subsection{Taxa de Desgaste}

A medição da taxa de desgaste foi obtida por meio de pesagem dos corpos de prova ao término de cada ciclo. Em todas as condições ensaiadas com exceção das amostras do grupo $\mathrm{E}$ atingiu-se o regime permanente de desgaste. Durante os testes ocorreram alguns fenômenos que interferiram nos ensaios realizados.

\subsubsection{Grupo A}

Para esta condição foram observadas taxas de desgaste médias nos valores de $0,053 \pm 0,004 \%$ de perda de massa por ciclo. Pode-se observar em destaque (Figura 4) uma turbulência no ensaio causada pelo desprendimento da lixa. Sanado o problema, o regime permanente é atingido imediatamente no ciclo posterior ao ocorrido. Este fato comprova a confiabilidade do ensaio.

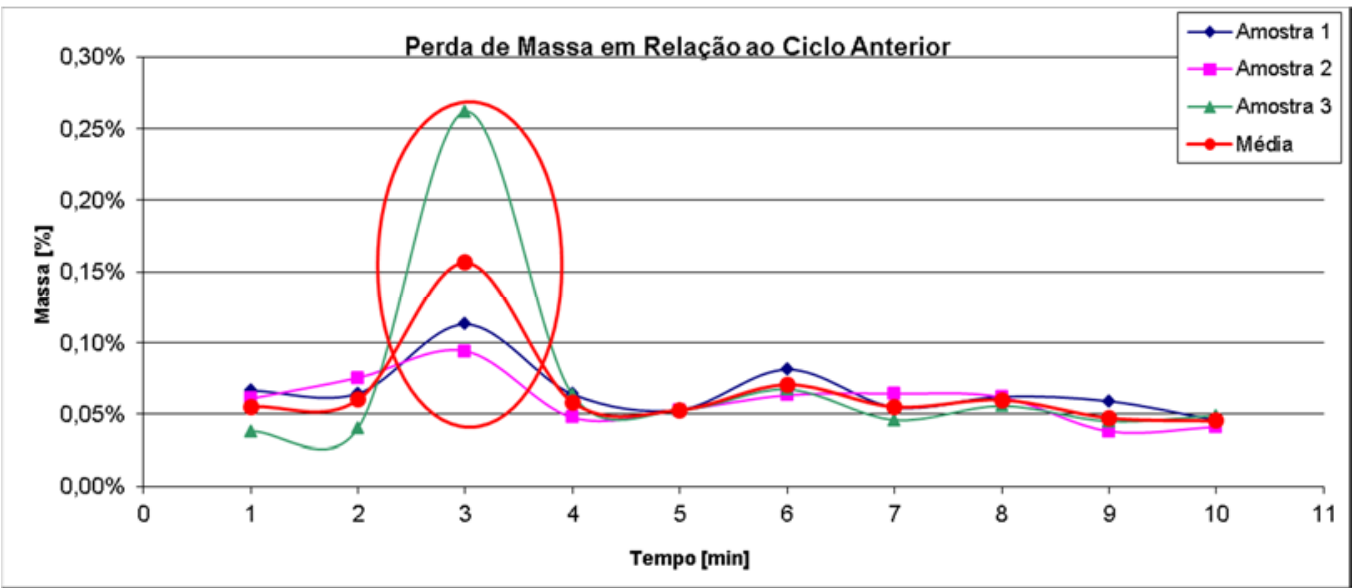

Figura 4. Grupo A. Taxa de desgaste para ensaios realizados.

\subsubsection{Grupo B}

Nesta condição pode-se observar que o comportamento das amostras durante todo o teste permanece com um padrão similar. A taxa de desgaste obtida foi de 0,027 \pm $0,004 \%$ (Figura 5).

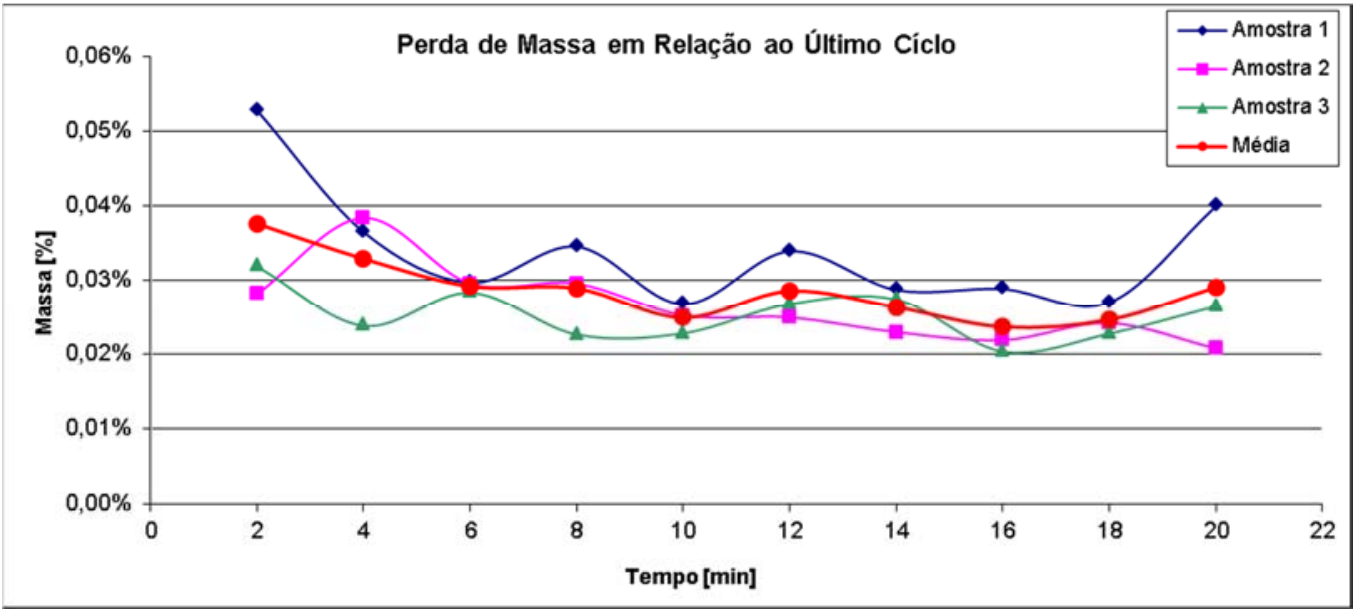

Figura 5. Taxa de desgaste para ensaios realizados na condição B. 


\subsubsection{Grupo C}

Nesta condição a taxa de desgaste encontrada foi de $0,085 \% \pm 0,004 \%$ como pode ser observado na Figura 6. Nota-se a turbulência inicial causada pelo efeito da preparação da superfície.

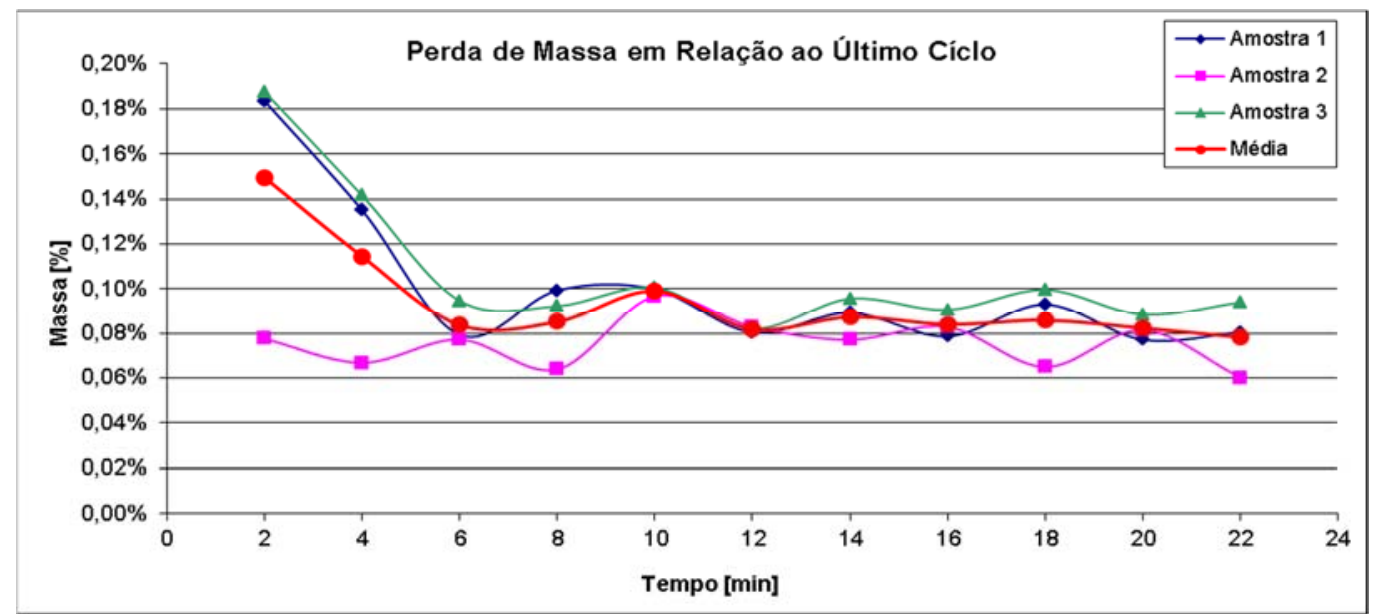

Figura 6. Taxa de desgaste para ensaios realizados na condição C.

\subsubsection{Grupo D}

Nesta condição ocorre uma turbulência causada pelo desprendimento da lixa (em destaque na figura 7) e foram observadas as maiores taxas de desgaste atingindo $0,149 \pm 0,004 \%$ (Figura 7 ).

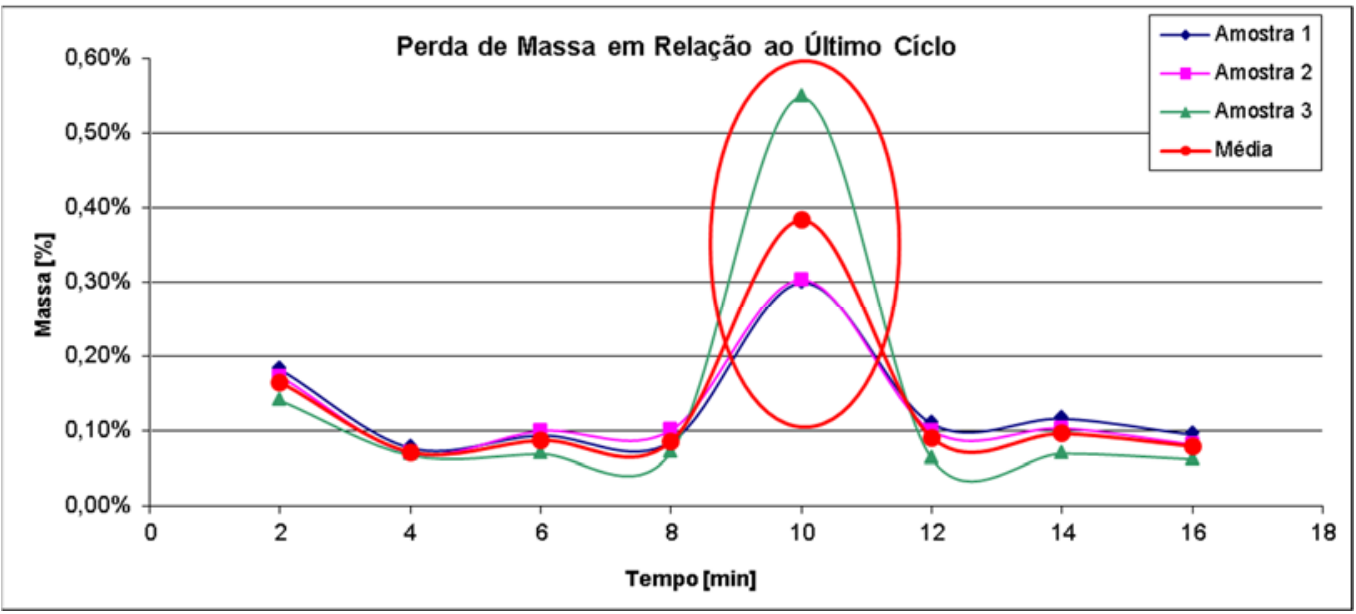

Figura 7. Taxa de desgaste para ensaios realizados na condição D.

\subsubsection{Grupo E}

Esta foi à condição na qual a duração dos ciclos foi a mais longa (3 minutos), onde a taxa de desgaste média encontrada foi de $0,073 \% \pm 0,011 \%$ (Figura 8). Durante o ensaio esta taxa decresce a cada ciclo, não configurando exatamente o regime permanente de desgaste. Houve neste caso o encruamento da superfície notado por um leve aumento de dureza superficial da amostra medido em um microdurômetro. 


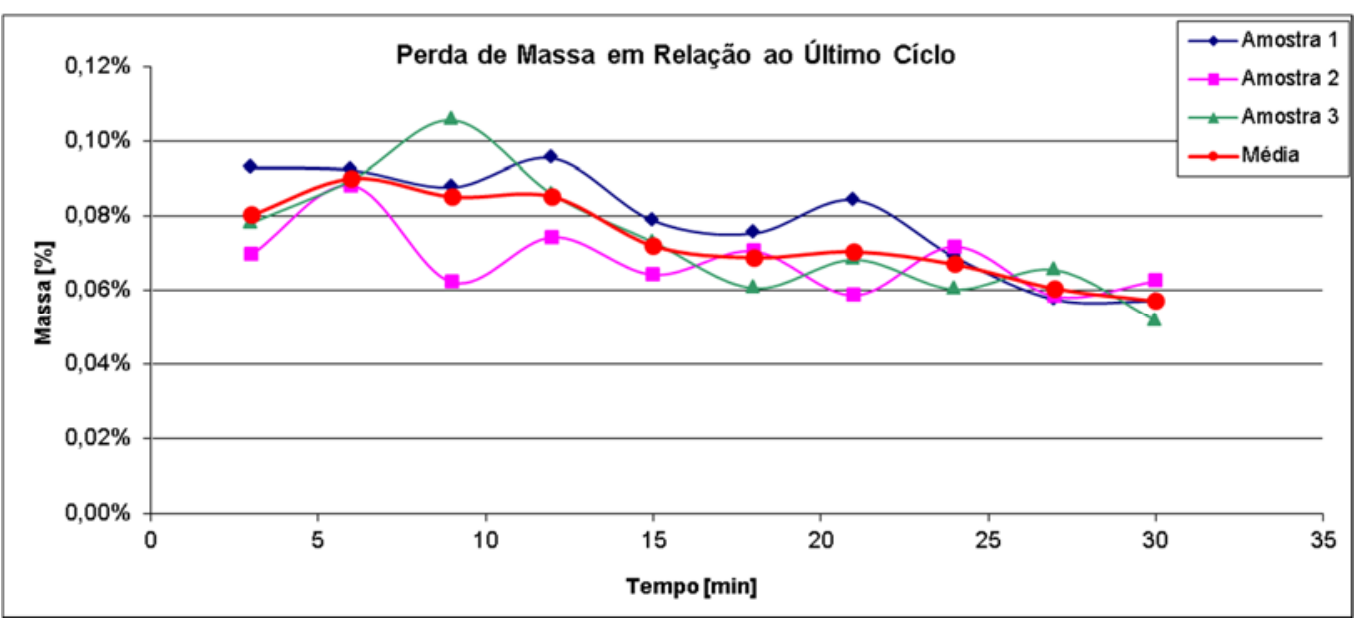

Figura 8. Taxa de desgaste para ensaios realizados na condição $\mathrm{E}$.

\subsection{Análise Perfilométrica}

Após os ciclos de desgaste, todos os grupos de amostras foram submetidos à análise perfilométrica para que fosse analisada a topografia da pista de desgaste. $O$ parâmetro St que mede a amplitude entre o pico máximo e o vale mais profundo da superfície da amostra, foi determinante para a escolha da condição ideal para a realização dos ensaios e esta condição foi à condição pertencente ao Grupo A. Nesta condição o valor de St foi maior que nas demais amostras atestando um melhor desempenho do abrasivo (Figura 9). Acredita-se que nessa condição de ensaio o principal mecanismo de desgaste seja o desgaste abrasivo por deslizamento devido à integridade da lixa abrasiva. Nas condições com baixos valores de St o abrasivo foi deteriorado e as pequenas partículas soltas do abrasivo poderiam causar um desgaste abrasivo por rolamento de partículas, alterando assim o mecanismo de desgaste.

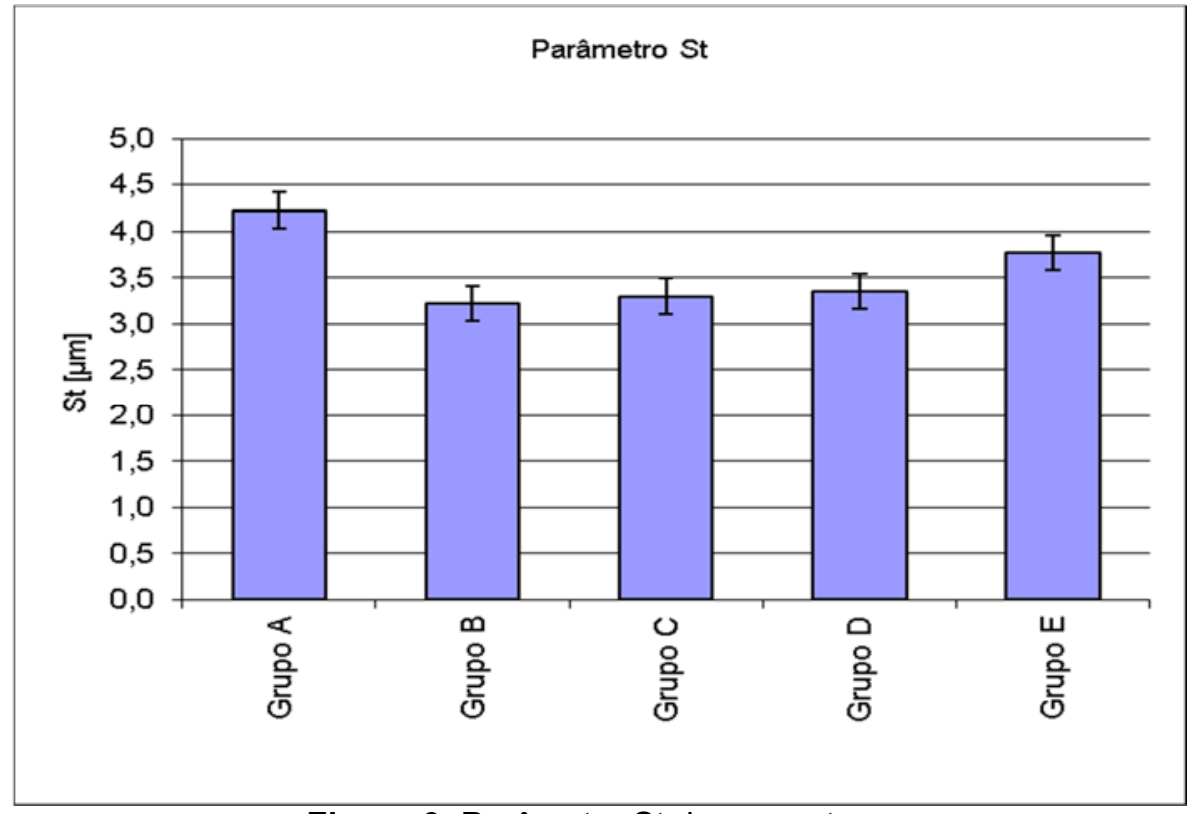

Figura 9. Parâmetro St das amostras. 


\subsection{Diferenças de Abrasivo}

Durante os testes foi notado que as lixas abrasivas de mesma malha e de mesmo fabricante apresentavam comportamento diferente em relação à umidificação sendo a lixas identificadas como 27E e 85C (Figura 10a e 10b). Esta mudança de abrasivo foi refletida no ensaio que apresenta uma redução na taxa de desgaste a partir do momento em que se muda de abrasivo, a linha tracejada determina o momento onde o abrasivo foi trocado (Figura 11), porém o fornecedor não soube explicar a diferença entre os dois abrasivos.

a)

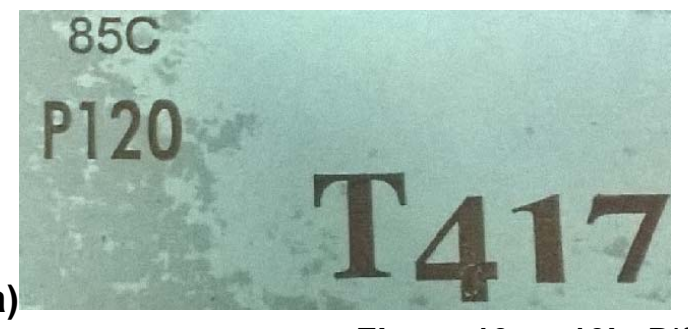

b)

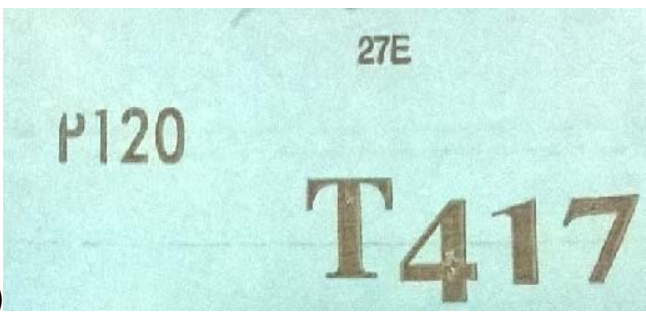

Figura 10a e 10b. Diferença nos abrasivos.

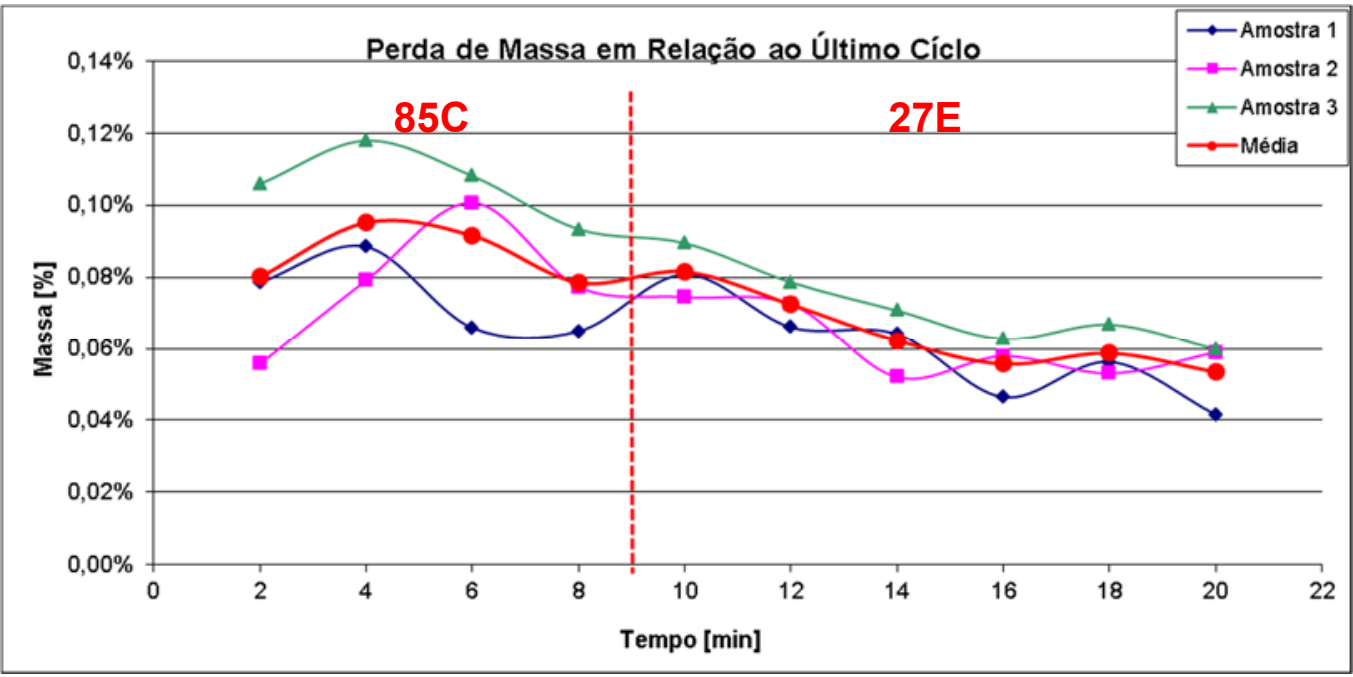

Figura 11. Queda na taxa de desgaste causada pela mudança de abrasivo.

\subsection{Comparação dos Materiais}

Após a determinação da condição ideal para realização dos ensaios (Tabela 3), os aços P410M, A36, P398A e P399A foram submetidos ao teste.

Tabela 3. Condição selecionada para ensaio.

\begin{tabular}{ccccccc}
\hline Grupo & $\begin{array}{c}\text { Tempo } \\
{[\mathrm{min}]}\end{array}$ & $\begin{array}{c}\text { Carga } \\
{[\mathrm{N}]}\end{array}$ & $\begin{array}{c}\text { Vazão } \\
{[\mathrm{ml} / \mathrm{s}]}\end{array}$ & RPM & Lixa & $\begin{array}{c}\text { Tipo de } \\
\text { Abrasivo }\end{array}$ \\
\hline $\mathrm{A}$ & 1 & 100 & 260 & 150 & 120 & $\mathrm{SiC}$ \\
\hline
\end{tabular}

Os aços inoxidáveis P399 e P398 obtiveram melhores resultados apresentando taxa de desgaste menor que os demais aços. O aço P410M apresentou um comportamento intermediário, apresentando desempenho melhor que os aços A36 e P410D que apresentaram o pior desempenho para a condição de ensaio e com um desempenho semelhante entre si. Na Figura 12 são expressos os valores médios a cada ciclo e na Figura 13 a média geral da taxa de desgaste. 


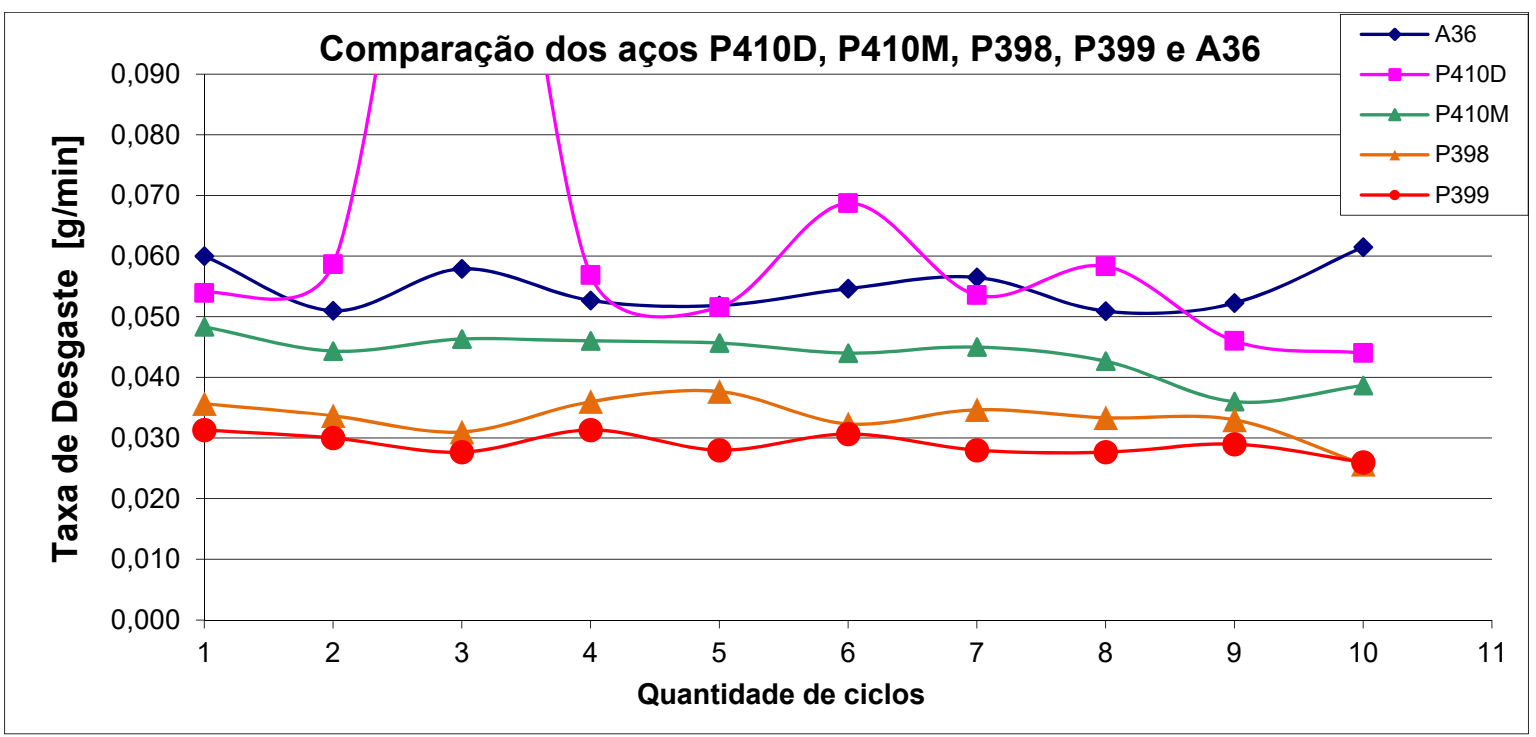

Figura 12. Comparação da taxa de desgaste por ciclo. Aços P398, P399, P410D, P410M e A36.

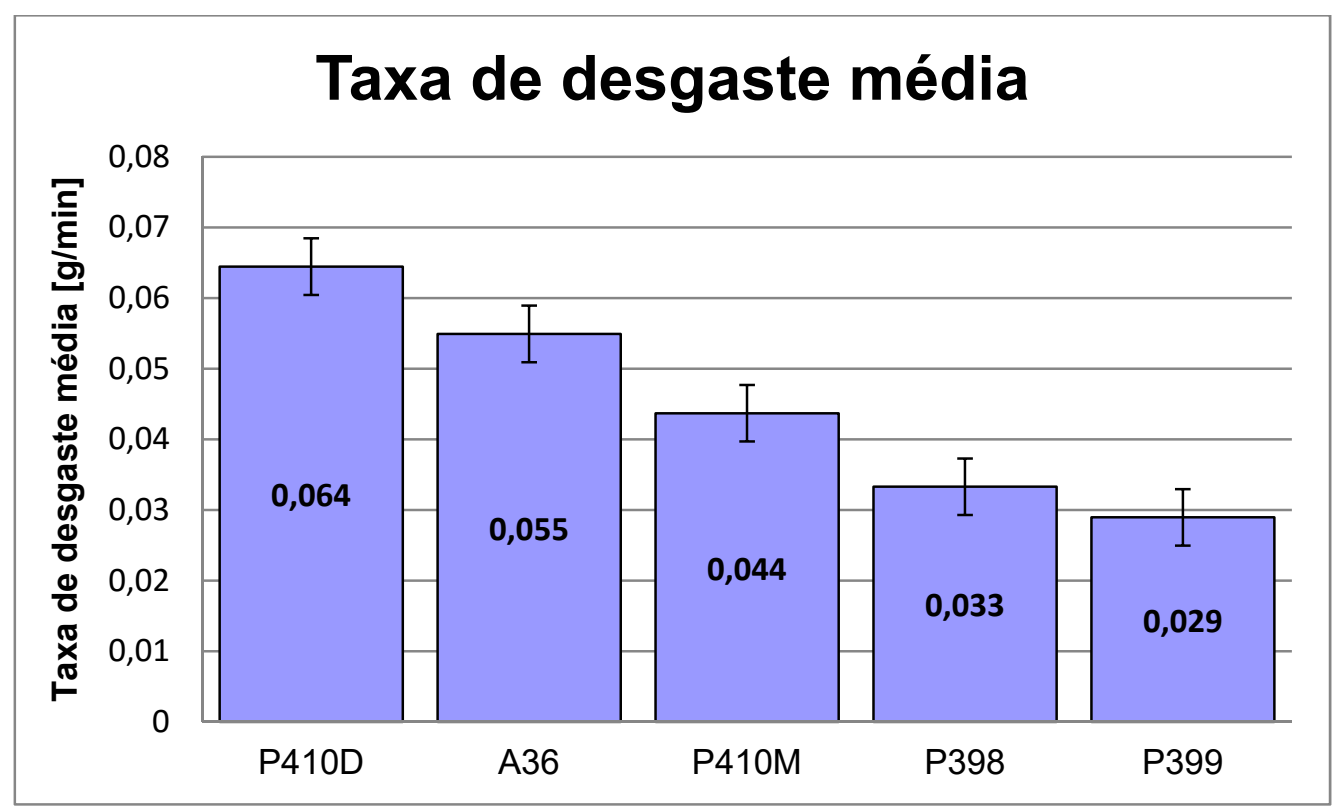

Figura 12. Taxa de desgaste dos aços P398, P399, P410D, P410M e A36.

O comportamento dos aços P410D e A36 já foram estudados e para os parâmetros e mecanismos utilizados na ocasião, apresentaram resultados diferente sendo o P410D mais resistente que o A36 em ensaios de desgaste microabrasivo [7], isto reforça a importância da reprodução de um tribossistema semelhante às condições de trabalho dos materiais. Como os demais aços não são comumente aplicados como componentes de desgaste, pouco têm se estudado a respeito destas propriedades nos mesmos.

\section{CONCLUSÃO}

Após os testes realizados pode-se concluir que a metodologia de ensaio proposta se mostra confiável para estabelecer taxas de desgaste para diferentes materiais e ranqueá-las. 
A metodologia é sensível o suficiente para detectar pequenos fenômenos que podem alterar as propriedades dos materiais ou fenômenos externos que podem interferir no resultado.

Trata-se de um ensaio pioneiro, cujas melhorias na metodologia ainda serão implantadas, como melhor controle de vazão de água.

Como trabalho futuro, estes materiais serão testados mudando a granulometria da lixa bem como o tipo de material abrasivo.

\section{Agradecimentos}

Agradeço a Aperam South América pelo fornecimento da bolsa de iniciação científica e por ter disponibilizado os equipamentos do Centro de Pesquisas da Aperam em Timóteo/MG

Agradeço ao Centro Universitário do Leste de Minas Gerais - UNILESTE pela oportunidade de participar deste projeto junto a Aperam South América.

\section{REFERÊNCIAS}

1 Czichos H, Habig KH. Tribologie Handbuch - Reibung und Verscleiß. Braunschweig: Vieweg Verlag; 1992.

2 Valécio M. Proteção da caçamba reduz custos. Minérios \& Minerales. 2015; v. 368, p.48.

3 ASTM G77, Standard Test Method for Ranking Resistance of Materials to Sliding Wear Using Block-on-Ring Wear Test, ASTM International, West Conshohocken, PA, 2010.

4 ASTM G40-15, Standard Terminology Relating to Wear and Erosion, ASTM International, West Conshohocken, PA, 2015.

5 Hutchings IM. Tribology: friction and wear of engineering materials. London: Edward Arnold; 1992.

6 Zum Gahr KH. Microstructure and wear of materials. New York: Elsevier; 1987.

7 Labiapari WS, Alcântara CM. Stainless Steel as an antiwear material for the bio-fuel industry. Wear. 2013; v. 302: p. 1536-1545. 